\title{
DEVELOPMENT OF VIBRATORY CAVITATION EROSION TEST SETUP AND ITS QUALIFICATION
}

\author{
Mr. Y.P.Ranerajput \\ Department of Mechanical Design Engineering \\ Rajarambapu Institute of Technology, Islampur, \\ Maharashtra, India \\ Mr. S.B.Pandharikar \\ Scientific Officer G \\ Bhabha Atomic Research Centre, Mumbai, \\ Maharashtra, India
}

\begin{abstract}
The formation of vapor or vapor and gas-filled bubbles in a liquid due to reduction in pressure is known as cavitation. Generally developed around pump impeller, propeller blades, torpedo etc. The usual parameters which affect cavitation damage are compressibility, viscosity $\&$ density, thermodynamic effect etc. Many types of machinery use water hydraulic system. Usually, the valves of the water hydraulic system show frequent failure. On observation, it is found that the rudimentary reason for the failure of components is Cavitation Erosion. Evaluation of Cavitation Erosion resistance for different materials shall give the required inputs for the selection of material for hydraulic valves. In this work, the vibratory cavitation test facility has been developed for the evaluation of erosion resistance of various materials. The details of the experimental setup of Vibratory Cavitation Erosion test setup, calibration and qualification of setup important parameters of vibratory cavitation test viz. standard test conditions, test specimen, the procedure of testing etc. and calibration \& qualification of test facility are explained. Mean depth of erosion, Erosion rate, $t_{50}$ (time required to erode $50 \mu \mathrm{m}$ depth), $\mathbf{t}_{100}$ and $\mathbf{t}_{200}$ are founded. The specimen of SS 316 takes 6 hours, 10.5-11 hours and 22 hours to $t_{50}, t_{100}$ and $t_{200}$ resp.
\end{abstract}

Keywords- Cavitation, Cavitation-erosion, Vibratory cavitation.

\section{INTRODUCTION}

When the liquid is heating under constant temperature, the pressure of a liquid is reduced below vapor pressure by static or dynamic means ultimately a state is reached at which vapor or vapor and gas-filled bubbles are formed known as cavitation There are several types of cavitation viz. Travelling cavitation, Vortex cavitation, Fixed cavitation and Vibratory

\author{
Prof. S.N.Jalwadi \\ Department of Mechanical Design Engineering \\ Rajarambapu Institute of Technology, Islampur, \\ Maharashtra, India
}

Mr. P.K.Limaye

Scientific Officer H, Head of Systems and Control Section, Bhabha Atomic Research Centre, Mumbai,

Maharashtra, India

Cavitation [1]. These cavities are travelling along with the flow and collapses when the pressure becomes higher than the vapor pressure. These cavities will damage the surface when collapsed on the wall or any surface. Cavitation damage is the most spectacular and well-known effect of cavitation. Cavitation harms the surfaces, objects by removing material from the surface. The process of removing material from the component's surface is known as cavitation erosion. Cavitation erosion is a complicated process of material debasement caused due to collision of bubbles in the proximity of solid surface. The cavitation erosion is like fatigue failure loss and is a time-dependent phenomenon. The surface undergoes deformation because of the development of complex stresses due to cyclic loading [2].

ASTM G 32-10[3] presented a method of testing for cavitation erosion using vibratory apparatus. B.K. Sreedhar et al.[4] reviewed on the work to understand damage due to cavitation also presented the bubble collapse theory, bubble collapse equations, estimation of bubble collapse pressure. They have compared the liquid properties affecting the cavitation damage. They also explained techniques of cavitation damage measurement viz. Water tunnel, venturi, rotating disc device, rotating wheel, vibratory cavitation device etc. H.X. Hu, Y.G. Zheng[5] compared the cavitation silt erosion and cavitation erosion in the pure water of stainless steel 304 in sand and analysis of effects of the particles and sand concentrations on the cavitation silt erosion were done. The result appears that with increasing sand particle concentrations, mass loss decreases. JIU-GEN HE and F. G. HAMMITT [7] compared the performance of cavitation erosion in the vibratory system and venturi system using tap water. They studied the effect of horn's amplitude, variation in temperature and velocity of venturi throat. The correlation has developed between Incubation period, Maximum erosion rate, material's mechanical properties (Brinell hardness and 
ultimate). Two sets of vibratory cavitation erosion test were performed. In the first test only tap water is used while in second test tap water along with abrasive silicon carbide is used. It was observed that mass loss is higher in the second test [8]. M. Szkodo [14] said that for ductile materials, ultimate fracture energy indicates resistance to cavitation erosion and when data from similar materials are compared then hardness can be an indicator of cavitation resistance.

Many problems have been observed in hydraulic systems due to cavitation erosion. In industrial applications, many machines use water hydraulic system. The components of the water hydraulic system show frequent failure. On observing the components, it was found that cavitation erosion is the rudimentary reason for component's failure. Hence to modify their component for prolonging life, the material of construction needs to be modified. Evaluation of various materials for cavitation erosion shall give the required inputs for material selection of components of the water hydraulic system. To measure the cavitation erosion of various materials it is required to test those materials. A standard test setup needs to be developed for such evaluation of materials. By surveying literature it is observed that Vibratory test setup is a standard test method and easy to develop on a lab scale. Therefore cavitation erosion test setup using the vibratory method has been developed for evaluation of cavitation erosion properties of various materials.

The paper is organised as follows. Development of Vibratory Test Setup is explained in section II. Calibration of apparatus is presented in section III. The procedure and guidelines for apparatus qualification are explained in section IV. Results and concluding remarks are given in section $\mathrm{V}$ and VI respectively.

\section{DEVELOPMENT OF VIBRATORY TEST SETUP}

The ASTM standard G32-10 has standardized test method for "Cavitation Erosion for Vibratory Apparatus" [3]. In this standardized test method, the procedure to evaluate loss due to cavitation on the specimen's face is observed while the specimen is immersed in water and vibrated at high frequency. According to the standard, equipment required for developing Vibratory Cavitation Erosion Test Setup is listed below.

i. Apparatus ii. Liquid Vessel iii. Test specimen iv. Weighing scale v. PID controller and Chiller vi. Ultrasonic Cleaner vii. Optical Microscope.
A. Apparatus:

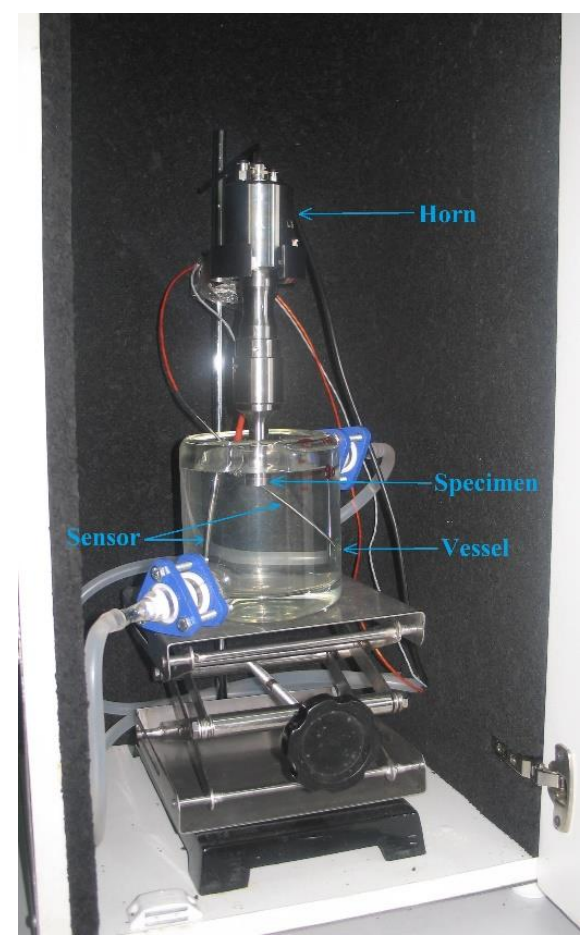

Fig. 1. Photograph of typical apparatus

The vibratory cavitation erosion apparatus is mostly used device for testing of cavitation erosion [3]. The apparatus is consists of vibrating transducer generally called as 'Horn', a vessel in which specimen is put into specified depth in the test liquid and power supply. The vessel has provided with a cooling bath (water jacket) to control the temperature of the test liquid. The piezoelectric transducer driven by an electronic oscillator and power amplifier generates the axial vibrations of a test specimen. An acoustic (Ultrasonic) power output of $250 \mathrm{~W}$ to $1000 \mathrm{~W}$ has been found suitable for this evaluation. This transducer is generally provided with a power adjustment facility that can be used to set and supervising vibration amplitude. The specimen is threaded to the vibrating Horn. The test specimen is a button in shape and has the same outer diameter as that of the horn tip. The specimen has threaded shank which is screwed into a threaded hole at the horn tip. The frequency of oscillations is $20 \pm 0.5 \mathrm{KHz}$ and amplitude is $50 \mu \mathrm{m} \pm 5 \%$ [3]. 


\section{B. Experimental Setup:}

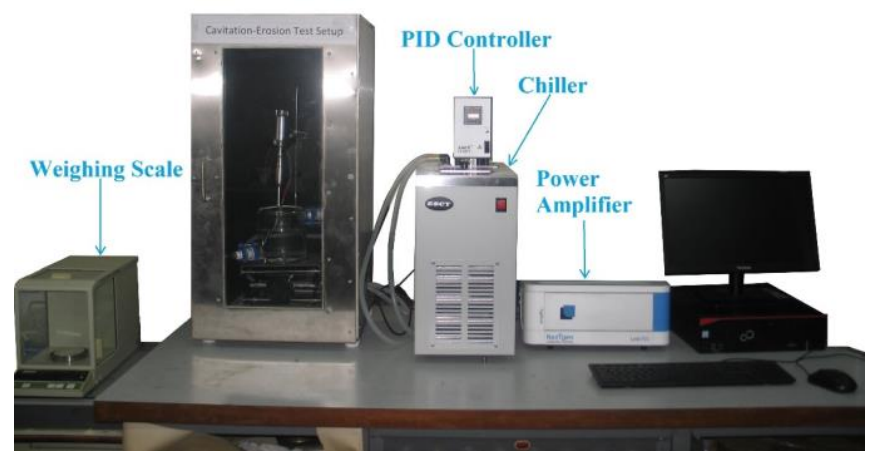

Fig. 2. Vibratory Cavitation erosion Test Setup

The Vibratory Cavitation erosion test setup has been developed by connecting all the required types of equipment and subcomponents. The transducer is connected to the power amplifier, ultimately transducer and power amplifier are connected to the Computer. The software required for the operation of power amplifier and transducer is installed in the computer through which we can control the desired inputs. A liquid vessel is specially designed and manufactured for this test. The liquid vessel has a water jacket around it. A specimen button is threaded into the transducer tip. Transducer basically called as 'Horn' is attached to a stand holder so that specimen button should be immersed into the liquid vessel. A chiller unit along with PID controller is installed beside the apparatus. A sensor is placed in the liquid vessel which is connected to the PID controller to control and maintain the desired temperature. Temperature-controlled water is circulated through the vessel jacket by chiller unit which helps to maintain the temperature of test liquid. Along with this equipment, weighing scale, ultrasonic cleaner and optical microscope have been used for along with this test setup. The photograph of developed Vibratory Cavitation Test Setup is shown above. The calibration of the developed apparatus must be done to ensure that our apparatus is working fine within the standards.

\section{CALIBRATION OF SETUP}

The correlation between a measured quantity and known measurement is known as calibration. The purpose of Calibration of measuring instruments is, to check the accuracy of the equipment and to tap the ability to verify the history of the measurement. ASTM standard provided different methods to compute the amplitude and calibration of the device [3]. The commercially obtained ultrasonic transducer has the provision to control the amplitude by power adjustment through control software. It is required to find out the power level which will generate the desired test condition of amplitude and frequency. Once the transducer is calibrated the same power adjustment can be used to supervise the amplitude of vibration [3].

\section{Calibration by Digital Dial Indicator :}

Dial Indicator method has been used to calibrate the apparatus. The tip of the dial indicator is touched to the surface of a specimen mounted in the horn to measure its displacement. This calibration is carried out in an air medium. While performing the calibration process with a dial indicator in air, transducers get heated due to high-frequency oscillation (20 $\mathrm{KHz}$.

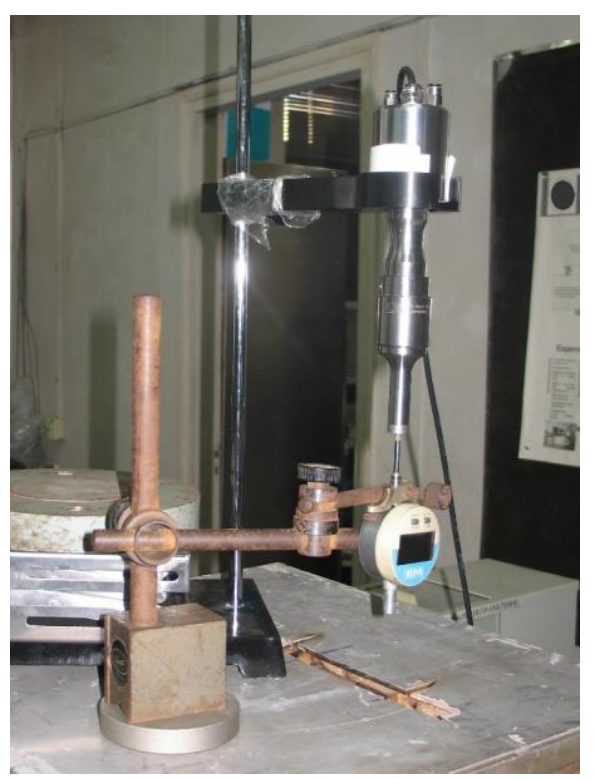

Fig. 3. Calibration by Digital Dial Indicator

As per ASTM guidelines, it is necessary to maintain the temperature $25 \pm 2^{\circ} \mathrm{C}$. Therefore we have to perform calibration with a dial indicator in the shortest time and intermittent cooling of the specimen using cold water. It is ensured that the dial indicator is fixed properly to the stand during this calibration. While performing calibration, the dial indicator should not move from the fixed position. The transducer is powered up and power to the transducer is increased till the transducer is vibrating at an amplitude of $50 \mu \mathrm{m}$. It was observed during this calibration that at $80 \%$ of the power the transducer is vibrating at $20 \mathrm{KHz}$ and $50 \mu \mathrm{m}$ amplitude. The disadvantage of this method is, the tip of the dial indicator may produce dent marks on specimen face. The calibration of the apparatus ensures that the vibrations produced by the transducer are compared with standard and those are matches to the standard. Even after the calibration, the apparatus can be used for testing of various materials if and only if the apparatus is qualifying the standard tests. Therefore to begin testing, qualification of apparatus is necessary. 


\section{QUALIFICATION OF APPARATUS}

To perform Qualification of apparatus, ASTM standard explained the guidelines that are to be used to qualify apparatus.
A. Guidelines for apparatus Qualification [3]:
1. Evaluation needed;
- Maximum erosion rate (MER) $(\mu \mathrm{m} / \mathrm{h})$,
- Nominal incubation time $\left(\mathrm{t}_{0}\right)(\mathrm{min})$,
- Time to mean depth of erosion $\left(\mathrm{t}_{50}, \mathrm{t}_{100}\right)(\mathrm{min})$.

2. Test shall be conducted on at least two or preferably more specimens. (Nickel-200 or SS 316)

3 . If the values of $t_{50}$ and $t_{100}$ are lies between the two standard deviations of the corresponding mean values from table 1 , then the apparatus is said to be 'Qualified'.

Table -1 Acceptability limits for qualification [3]

\begin{tabular}{|c|c|c|c|c|c|}
\hline $\begin{array}{c}\text { Reference } \\
\text { Material }\end{array}$ & Parameter & $\begin{array}{c}\text { Mean } \\
(\mathbf{X}) \text { of } \\
\text { Lab } \\
\text { Results }\end{array}$ & $\begin{array}{c}\text { Std. } \\
\text { Deviation, } \\
\text { S }\end{array}$ & $\begin{array}{c}\text { Upper } \\
\text { Limit } \\
\mathbf{X + 2 S}\end{array}$ & $\begin{array}{c}\text { Lower } \\
\text { Limit } \\
\mathbf{X - 2 s}\end{array}$ \\
\hline 316 & MER & 9.1 & 1.0 & 11.1 & 7.1 \\
Stainless & $\mathrm{t}_{50}$ & 378 & 34 & 445 & 310 \\
Steel & $\mathrm{t}_{100}$ & 667 & 26 & 719 & 615 \\
\hline
\end{tabular}

\section{B. Test Conditions:}

1. Test liquid should be distilled or deionized water.

2 . Depth of water in container $100 \pm 10 \mathrm{~mm}$ with cooling coils placed.

3. Sinking base of specimen test surface: $12 \pm 4 \mathrm{~mm}$.

4. Specimen shall be coaxial to a container within $\pm 5 \%$ of container diameter.

5. Air should be surrounding gas over test liquid. Maintain standard atmospheric pressure.

6. Peak to peak displacement of amplitude: $50 \mathrm{um} \pm 5 \%$.

\section{The Procedure of Testing:}

1. Clear the liquid vessel. Pour the fresh liquid (For every new test) (or after 8 hours of testing)

2. Clean the test specimen. Weigh it carefully \& accurately.

3. Ensure that threads of horn and specimen button are free from debris and dust.

4. Thread the specimen button into horn by calculated torque. Make sure the prestressing in horn's threads and shank.

5. Insert specimen into the liquid, and remember test conditions

6. Set amplitude of the horn's vibration as $50 \mu \mathrm{m} \pm 5 \%$ (peak to peak) and frequency $20 \pm 0.5 \mathrm{KHz}$. Start apparatus, timer.

7. After testing, follow these steps;

- Remove specimen. Put it into the beaker, fill acetone in the beaker until specimen immersed completely.

- Clean it carefully by ultrasonic cleaning bath.
- Dry it by hot steam or hairdryer. (Don't dry with cloth or paper)

- Weigh it carefully on accurate and sensitive balance. 8. Repeat the procedure for the next pre-determined interval.

By following the procedure as suggested by ASTM, testing on five samples of SS 316 has been completed.

\section{RESUlts}

The 5 sample specimen of SS 316 for the qualification of apparatus were selected. Out of 5 samples the 3 were tested for $\mathrm{t}_{50} \& \mathrm{t}_{100}$ i.e. time required to erode $50 \mu \mathrm{m} \mathrm{MDE}$ and 100 $\mu \mathrm{m}$ MDE resp. and 2 were tested for terminal erosion rate. The important step in the test is recording the mass of the specimen before and after the test. By recording the mass of specimen before the test and mass after each test interval, values of mass loss and volume loss have been calculated. The surface area of the test specimen is calculated. The test specimen details are given below. The details below show the values of $t_{50}, t_{100}$ and time of terminal erosion rate for one of five samples.

$$
\begin{aligned}
& \mathrm{t}_{50}=390 \text { minutes } \\
& \mathrm{t}_{100}=690 \text { minutes } \\
& \mathrm{t}_{200}=1320 \text { minutes } \\
& \text { Maximum Erosion Rate }=8.0838 \mu \mathrm{m} / \mathrm{hr} .
\end{aligned}
$$

The main result of cavitation erosion test is the plot of cumulative erosion vs time. The original raw data will be in terms of mass loss vs time but for analysis and reporting these results should be reformed into a "mean depth of erosion" (MDE) vs time. Volumetric loss is more useful and convincing than a mass loss when materials of different densities are compared. The mean depth of erosion is calculated, for this test method based on the surface area of the test specimen. To compare erosion resistance of different materials, we can compare the $t_{50}$ (Time to erode $50 \mu \mathrm{m}$ depth), $\mathrm{t}_{100}$. The graph has been plotted between Mean Depth of Erosion \& Time and Erosion rate \& Time based on the results obtained.

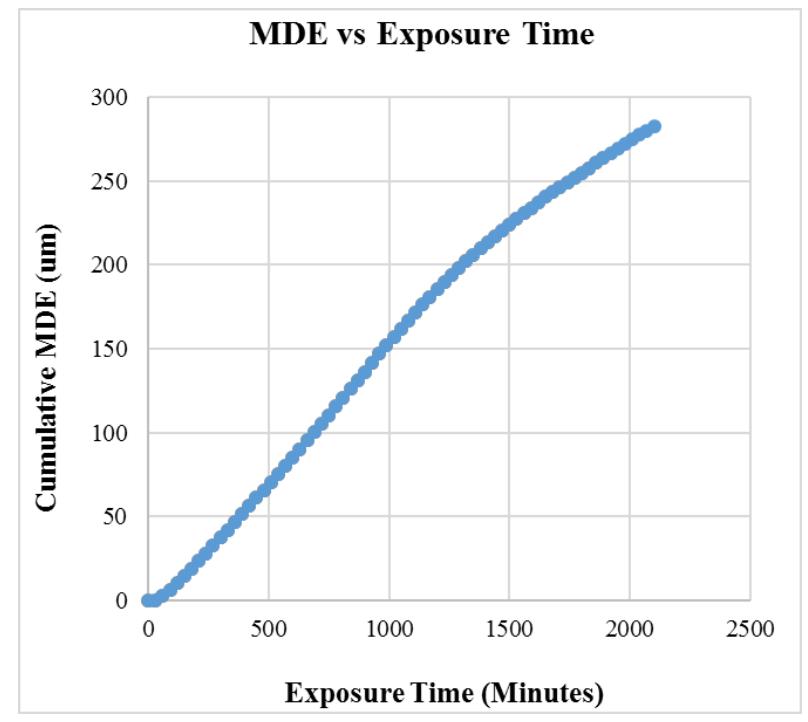


Fig. 4. Graph of MDE vs Exposure Time

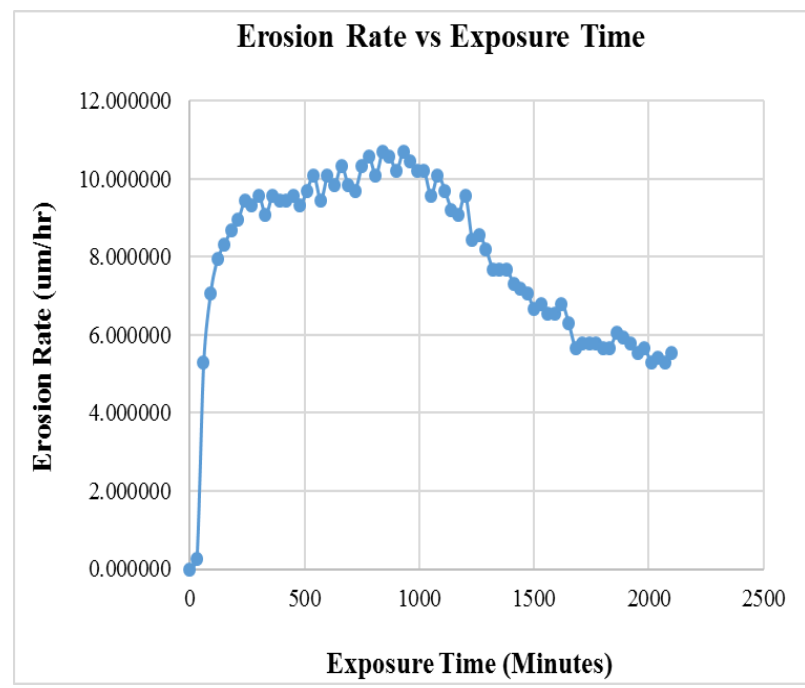

Fig. 5. Graph of Erosion Rate vs Exposure Time

Table 1 shows the acceptability limits for SS 316 material. Based on the lab results, the values of Mean and Standard deviation of $\mathrm{t}_{50}$ and $\mathrm{t}_{100}$ are shown in table 2 .

Table -2 Results for the qualification of SS 316

\begin{tabular}{|c|c|c|c|}
\hline $\begin{array}{c}\text { Tested } \\
\text { Material }\end{array}$ & Parameter & $\begin{array}{c}\text { Mean } \\
\text { of Lab } \\
\text { Results }\end{array}$ & $\begin{array}{c}\text { Std. } \\
\text { Deviation, } \\
\text { S }\end{array}$ \\
\hline 316 & MER & 9.042 & 0.68 \\
Stainless & $\mathrm{t}_{50}$ & 360 & 12 \\
Steel & $\mathrm{t}_{100}$ & 660 & 18.98 \\
\hline
\end{tabular}

Fig. 6 Photographs specimen taken at different exposure of time

In Fig.4, after the erosion threshold time, Mean depth of erosion is increasing with cumulative exposure time. In Fig.5 the erosion rate is increased drastically after the erosion threshold time and then remains almost constant up to MDE of $180 \mu \mathrm{m}$. After 1200 minutes of exposure the curve started declining which indicates the erosion rate has been decreasing with exposure time. The experiment is carried out up to the terminal erosion and found the terminal erosion rate as 5.5427 $\mu \mathrm{m} / \mathrm{hr}$ after 2100 minutes exposure of time. After the 1650 minutes of testing the graph of Erosion Rate vs Exposure Time becomes asymptote.

The digital images of specimen surface after cavitation erosion at different exposure of time while testing is presented in Fig. 6. The perimeter encountered less cavitation erosion, there is more damage as compared to the centre of the

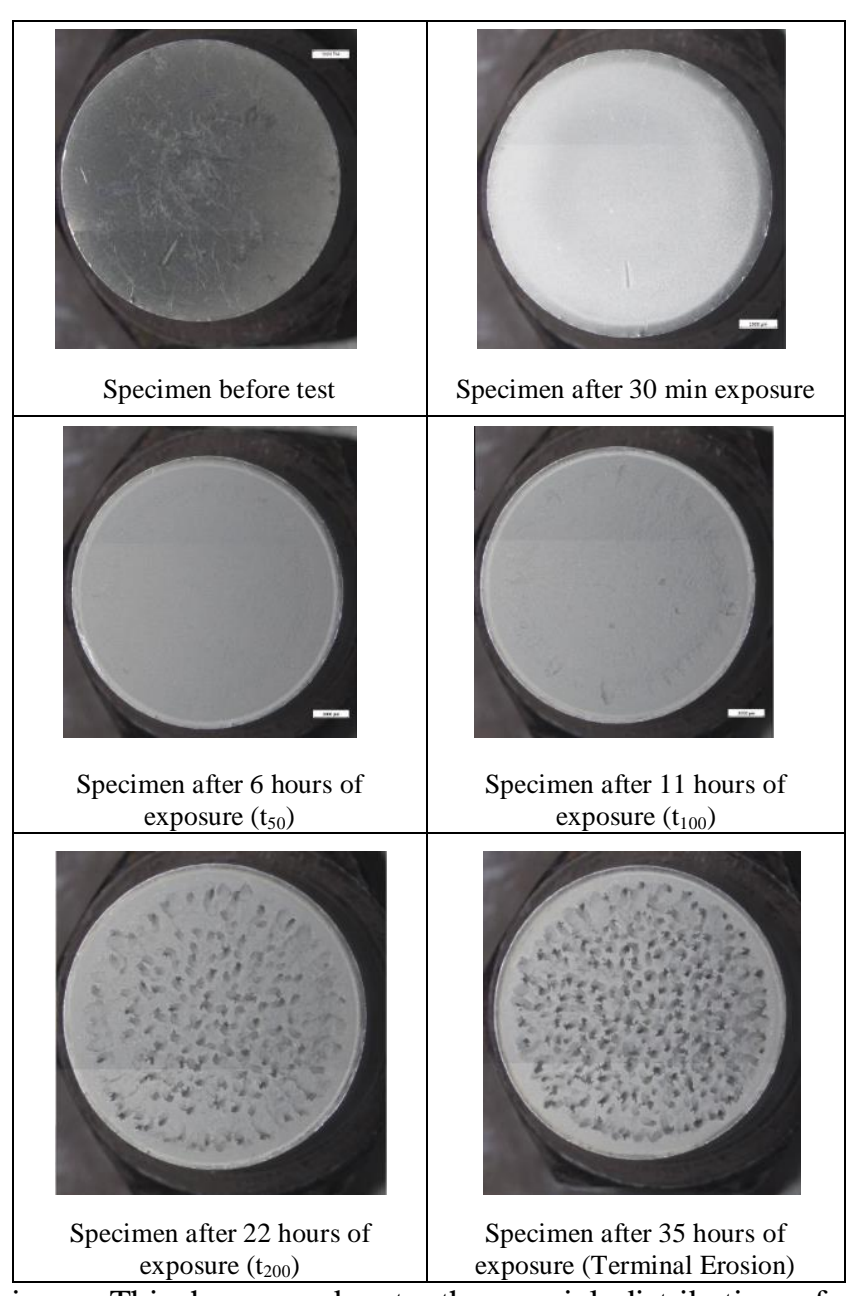

specimen. This happens due to the special distribution of bubbles while vibratory cavitation. By comparing the original perimeter, after the erosion of specimen, a ring-like region can be distinguished and pits are formed around the centre of specimen [4]. The differences in colour of the specimen between two distinct erosion region are due to cumulative exposure of specimen in liquid while testing which indicates different erosion mechanism. After 11 hours of exposure of specimen, the formation of the pits has begun near the edge of the specimen. As we increase the exposure time of specimen, the formation of the pit on the face of a specimen is increasing gradually towards the centre of the specimen. After 22 hours of exposure, we can see that the central region of the specimen is full of pits. We have executed test up to the terminal erosion, the complete area of the face of specimen is occupied by pits and we can observe that on the edge of specimen's face there are no any formation pits.

\section{CONCLUSION}

Cavitation, cavitation-erosion and cavitation damage are studied based on cavitation erosion of valves of water hydraulic system. The vibratory cavitation test method is a well-known and standardized experimental technique to 
measure erosion of materials. For the measurement of cavitation erosion, the vibratory test method is selected and the experimental setup for vibratory cavitation-erosion has been developed. The experimental test setup is calibrated by a digital dial indicator.

Five samples of SS-316 have been tested. From those five samples, three samples were tested for $t_{50}$ and $t_{100}$ and it is found that cavitation will erode $50 \mu \mathrm{m}$ mean depth in 6 hours $\left(\mathrm{t}_{50}\right)$ and $100 \mu \mathrm{m}$ in $10.5-11$ hours $\left(\mathrm{t}_{100}\right)$.

Two samples were tested for terminal erosion rate. It is observed that it takes 6 hours, 10.5-11 hours and 22 hours to arrive cumulative mean depth of erosion of $50 \mu \mathrm{m}\left(\mathrm{t}_{50}\right), 100 \mu \mathrm{m}$ $\left(\mathrm{t}_{100}\right)$ and $200 \mu \mathrm{m}\left(\mathrm{t}_{200}\right)$. The plot of erosion rate vs exposure time is gets asymptote after 1650 minutes of exposure.

From table 1 and table 2, the test results lie between the values of acceptability limit for SS-316 given by ASTM standard. Hence, it can be concluded that the "Vibratory Cavitation Erosion Test Setup' has been qualified.

\section{ACKNOWLEDGEMENT}

I would like to thank Prof. S.N.Jalwadi, Shri P. K. Limaye and Shri. S.B.Pandharikar for their valuable guidance \& support. I am grateful to Bhabha Atomic Research Centre, Mumbai for providing the opportunity to conduct this experimental work presented in this paper. I extremely thankful to faculty teaching and non-teaching staff of the department, central library and colleagues. Many people made valuable contributions to the development of this project. I appreciate their co-operation and a great help.

\section{REFERENCE}

[1] KNAPP ROBERT T., DAILY JAMES W. and HAMMITT FREDERICK G., "CAVITATION", McGRAW-HILL BOOK COMPANY, 363-393, (Pg 119).

[2] Sreedhar B.K., Albert S.K. and Pandit A.B., (2017), Cavitation damage: Theory and measurements - A review, Wear 372-373, (Pg 177-196).

[3] ASTM International G32-10, (2011), "Standard Test Method for Cavitation Erosion Using Vibratory Apparatus".

[4] Krella A. K. and Zakrzewska D. E., (2018), "CAVITATION EROSION - PHENOMENON AND TEST RIGS", ADVANCES IN MATERIALS SCIENCE, Vol. 18, No. 2 (56).

[5] Hu H.X. and Zheng Y.G., (2017), "The effect of sand particle concentrations on the vibratory cavitation erosion", Wear 384-385, (Pg 95-105).

[6] Sreedhar B.K., Albert S.K. and Pandit A.B., (2015), "Cavitation erosion testing of austenitic stainless steel (316L) in liquid sodium”, Wear 328-329, (Pg 436-442).
[7] HE JIU-GEN and HAMMITT F. G., (1982), "COMPARISON OF CAVITATION EROSION TEST RESULTS FROM VENTURI AND VIBRATORY FACILITIES", Wear, 76, (Pg 269 - 292).

[8] Laguna-Camacho J.R., M.Vite-Torres R.Lewis, and Me'ndez-Me'ndez J.V., (2013), "A study of cavitation erosion on engineering materials", Wear 301, (Pg 467476).

[9] ZHOU* YU-KANG and HAMMITT F. G., (1983), "VIBRATORY CAVITATION EROSION IN AQUEOUS SOLUTIONS”, Wear, 87, (Pg 163 - 171).

[10] Hammitt*t F. G. and Rogers* D. O., (1970) "EFFECTS OF PRESSURE AND TEMPERATURE VARIATION IN VIBRATORY CAVITATION DAMAGE TEST", Journal Mechanical Engineering Science Vol 12 No 6.

[11] He Yongyong and Shen Zaiyang, "Experimental Research on Cavitation Erosion Detection Based on Acoustic Emission Technique" 30th European Conference on Acoustic Emission Testing \& 7th International Conference on Acoustic Emission.

[12] Marques Paulo Villani and Trevisan Roseana da Exaltaçao, (1998), "An SEM-Based Method for the Evaluation of the Cavitation Erosion Behavior of Materials" MATERIALS CHARACTERIZATION 41, (Pg 193-200).

[13] Ahnted S. M., Hokkirigawa K., Itob Y. and R. Obab, (1991), "Scanning electron microscopy observation on the incubation period of vibratory cavitation erosion", Wear, 142,(Pg 303-314).

[14] Szkodo M., (2005), 'Mathematical description and evaluation of cavitation erosion resistance of materials', Journal of Materials Processing Technology 164-165 (Pg 1631-1636). 